\title{
LAND DEGRADATION ANALYSIS ON COASTAL AREA OF AMPARA DISTRICT
}

\author{
Dr. MIM. Kaleel \\ Senior Lecturer in Geography, Department of Geography, South Eastern University of Sri Lanka, \\ Sri Lanka. \\ kaleelmim@yahoo.com
}

\section{Keywords: GIS, Land Degradation, Salinization, Soil Erosion}

\begin{abstract}
The island of Sri Lanka is free from serious natural hazards such as volcanic activity and earthquakes resulting from climatic extremes, but there are impacts of many natural disasters, such as landslides, floods and droughts, the intensity and frequency of which are increasing due to human interventions. Some areas of Sri Lanka are also periodically subject to cyclones that occur due to climatic conditions and geographical locations.

Land degradation denotes all natural or anthropogenic processes that diminish or impair productivity of land. This occurs mainly through soil erosion, loss of organic matter and nutrients in the soil; salinization and large scale land degradation in Sri Lanka. Its manifestations today are heavy loss of soil, siltation in the water bodies, reservoirs and coastal waters, unplanned settlements, loss of arable land leading to declining productivity in agricultural lands and intensification of impacts of natural hazards such as flooding and landslides.

Land degradation is a major problem in Eastern Coastal Area from Kalmunai MC, Karaitivu and Nintavur Divisional Secretariat Divisions (DSDs) of Ampara District. However, there is a considerable spatial heterogeneity exists within this area in terms of land use, topography, land management and socio-economic conditions. Therefore, land degradation assessment studies are very important for the sustainable development of the area. Considering the above background, this study was conducted with the objectives of developing a land degradation assessment model using a GIS based approach.
\end{abstract}

\section{Introduction}

Land degradation is a dynamic process and is the result of both natural and biotic forces operating on the earth. The scientific information of degraded lands is thus essential for formulation of strategic plan to arrest the menace of land degradation, generation of realistic information on degraded lands of the country is the utmost necessity and taken on a mission mode in order to check further degradation of the environment and loss of top fertile soils [3].

Land degradation is a dynamic process operating on the earth due to natural biotic forces and human activities. Development of degraded lands is one of the options available for the growing population and to restore the fragile ecosystems in Sri Lanka. The information on the extent and spatial distribution of various kinds of degraded lands is thus essential for strategic planning [5]. Soil is a dynamic non-renewable resource which is essential for the continued agricultural productivity and to prevent degradation.

As long as the soil and land are used according to their potentials, it is good, continued unplanned and unscientific exploitation results in land degradation. The information on land degradation is needed for a variety of purposes, like planning the reclamation programmes. The land degradation problem has reached an alarming proposition due to various factors like over exploitation and mismanagement of natural resources and socio-economic factors [1].

The concern for protecting the productivity of natural resources without further degradation is the key issue for both the developed and the developing nations to sustain the future generations. The satellite remote sensing and GIS technologies should be fully utilized for monitoring the land degradation [6]. 
Land degradation, including soil erosion, continues to be a global constraint to economic development. Despite decades of efforts to arrest land degradation, many farmers are reluctant or unable to adopt appropriate land use practices. Often, these practices fail to combine high productivity, increased soil fertility, reduced soil erosion and enhanced welfare [7]. Still, soil conservation is proposed as a viable route to obtain these objectives.

The methodology for land degradation mapping, using remote sensing techniques developed by the organization, is based on the expertise in the field of soil survey and remote sensing acquired since inception. Database with spatial distribution of various soil and land attributes is a pre-requisite for development of strategic planning of any land development programme.

The information system on degraded lands in the country could be developed using remote sensing and geographical information systems towards strategic development of degraded lands and monitoring the status in a periodic timescale [2].

\section{Study area}

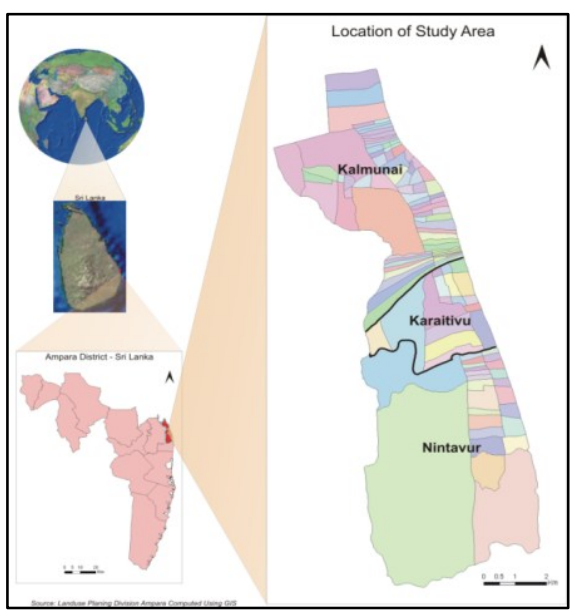

The study area is located in between the latitudes of $7^{\circ} 25^{\prime} 24^{\prime \prime}$ $\mathrm{N}$ and $7^{\circ} 27^{\prime} 25^{\prime \prime} \mathrm{N}$ and the longitudes of $81^{\circ} 45^{\prime} 31^{\prime \prime} \mathrm{E}$ and $81^{\circ}$ 50 ' 32 " E. The topography of this is mainly an undulating flat land. The population of this area is 648,057. The district consists of 20 Divisional Secretariat areas, 505 Grama Niladhari, Divisions and 828 villages. Of these, Kalmunai MC, Karativu and Nintavur DSDs were selected for the study. It has an extent of $67.91 \mathrm{~km} 2$ and its total population is 144995 , population density 2135 person per $\mathrm{Km}^{2}$.

Fig. 1. Study Area

(Source: Computed using GIS, 2008)

These people main occupation is paddy cultivation and also do the home gardening, they have maximum utilized the land for cultivation and other development. This over usage is caused to the land degradation.

\section{Objectives}

1. To identify the areas under threats of severe land degradation

2. To suggest require special conservation measures

\section{Materials and Method}

\section{Primary Data Collection}

The primary data have been collected through the questionnaire survey, by personal observation and interviews with the local and regional leaders of the inhabitants. The data have been generated for 6 divisional secretariat areas on related variables from 450 sample households, widely scattered in the study area. The following procedure of collecting data has been adhered to, for complete area coverage:

1. Land use change for every $1500 \mathrm{~m}$;

2. First 200 sample within $1.5 \mathrm{~km}$;

3. Next 150 sample in between $1.5 \mathrm{~km}$ to $3.0 \mathrm{~km}$;

4. Last 100 samples from distance more than $4 \mathrm{~km}$. 
Table 1. Sample from selected areas

\begin{tabular}{|l|r|r|r|r|r|}
\hline \multicolumn{1}{|c|}{ Areas } & $\begin{array}{r}\text { Sample 0 } \\
\text { to 1500m }\end{array}$ & \multicolumn{1}{c|}{$\begin{array}{c}\text { Sample } \\
\mathbf{1 5 0 0 m} \text { to } \\
\mathbf{3 0 0 0}\end{array}$} & $\begin{array}{c}\text { Sample } \\
\mathbf{3 0 0 0 m} \text { to } \\
\mathbf{4 0 0 0 m}\end{array}$ & Total Sample & $\begin{array}{c}\text { Per cent } \\
\text { (\%) }\end{array}$ \\
\hline Kalmunai & 56 & 35 & 27 & 118 & 26.2 \\
\hline Sainthamaruthu & 56 & 38 & 30 & 124 & 27.6 \\
\hline Karaitivu & 51 & 35 & 26 & 112 & 24.8 \\
\hline Nintavur & 48 & 27 & 21 & 96 & 21.4 \\
\hline Total & $\mathbf{2 1 1}$ & $\mathbf{1 3 5}$ & $\mathbf{1 0 4}$ & $\mathbf{4 5 0}$ & $\mathbf{1 0 0 . 0}$ \\
\hline
\end{tabular}

(Source: Field work, 2015)

\section{Secondary Data Collection}

The secondary data have been collected from the published and unpublished data sources.

- Published / Unpublished (earlier) studies

- Government documents and reports

- Private (NGOs) sources

- Remote sensing Analysis

- Printed maps

The following spatial and non-spatial data were used in this study:

1. Spatial data on Contour, Soil, Land use, Streams, Reservoirs, Road map of 1:50,000 scale topographic maps of the Survey Department of Sri Lanka,

2. Demographic data (Population Density, Education, Income, Land to man ratio, and agro land to man ratio), ground truth information. Further the spatial data analysis was carried out using Arc GIS 9.3.

\section{Data Analysis}

The land degradation severity map was prepared by integrating all spatial data layers. Weights were given to each spatial data layers according to their possible contribution towards soil erosion. Since rainfall induced soil erosion is the most influential factor in land degradation, more weight was assigned to this data layer during the analysis. The assigned weightage values are shown in Table 1.

Table 2. Weightage values for different spatial data type

\begin{tabular}{|l|c|}
\hline \multicolumn{1}{|c|}{ Spatial data type } & Weightage (\%) \\
\hline Soil loss & 45 \\
\hline Population density & 25 \\
\hline Agro land-man ratio & 15 \\
\hline Land-man ratio & 10 \\
\hline Samurdhi beneficiaries & 05 \\
\hline
\end{tabular}

Land degradation severity was assessed by using Weighted Sum algorithm in ArcGIS software. Applying simple arithmetic calculations, final land degradation map was produced for the period of 1981 to 2014. 


\section{Results and Discussion}

An analysis about the overall patterns of gain and loss of different categories of land degradation provides greater insights into an understanding of the changes in land uses and resultant degradation. Table 2 shows the net changes in gains and losses due to degradation of land during 1981-1991, 1991-2001, 2001-2006, 2006-2014 and 1981-2014 in the study area.

Table 3. Land Degradation in Study area (extent in $\mathrm{km}^{2}$ ) 1981-2014

\begin{tabular}{|l|r|r|r|r|r|}
\hline $\begin{array}{l}\text { Classification } \\
\text { Degraded }\end{array}$ & \multicolumn{1}{c|}{$\mathbf{1 9 8 1}$} & \multicolumn{1}{c|}{$\mathbf{1 9 9 1}$} & \multicolumn{1}{c|}{$\mathbf{2 0 0 1}$} & \multicolumn{1}{c|}{$\mathbf{2 0 0 6}$} & \multicolumn{1}{c|}{$\mathbf{2 0 1 4}$} \\
\hline Highly & 14.30 & 15.79 & 16.75 & 18.62 & 19.54 \\
\hline Moderately & 9.73 & 10.04 & 9.80 & 10.11 & 9.36 \\
\hline Less & 9.71 & 10.45 & 11.10 & 11.18 & 11.51 \\
\hline Non & 34.17 & 31.63 & 30.26 & 28.00 & 27.5 \\
\hline Total & 67.91 & 67.91 & 67.91 & 67.91 & 67.91 \\
\hline
\end{tabular}

Source: Field measurements and Computation using GIS (Kaleel, 2015)

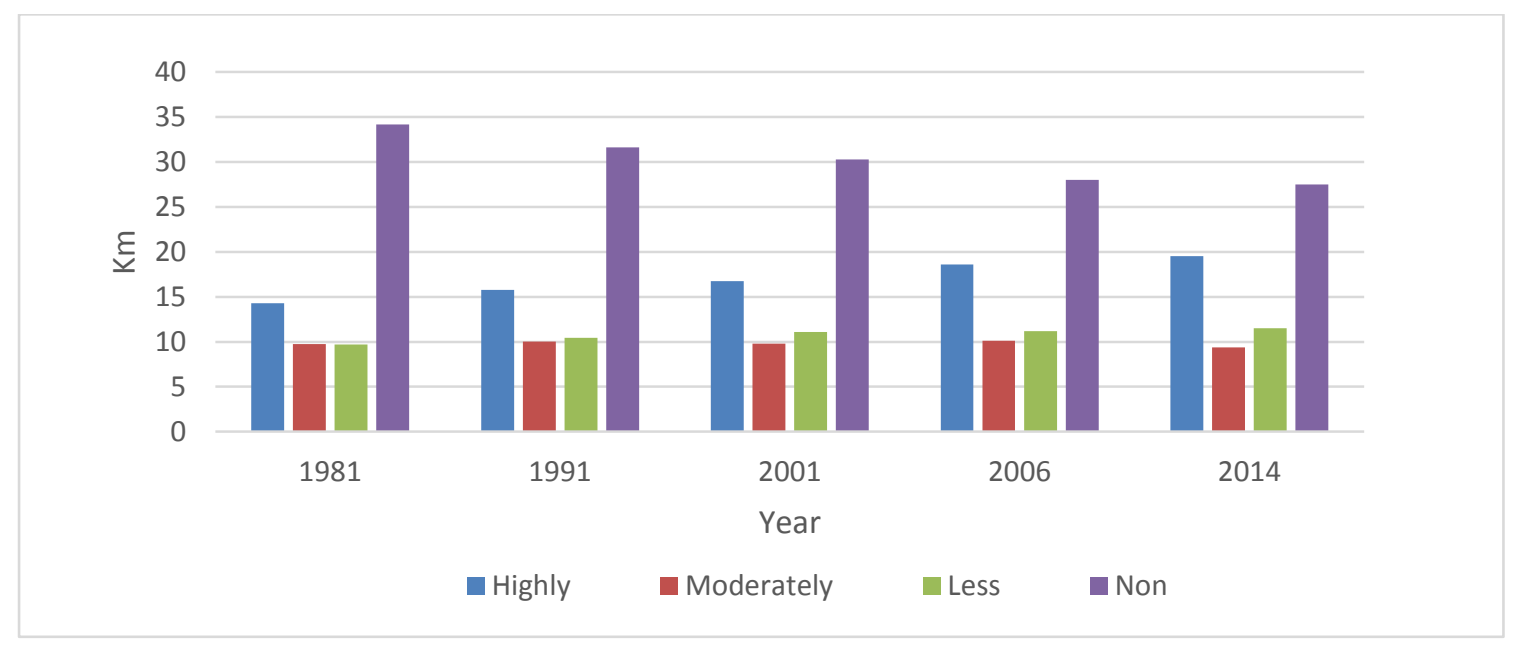

Fig. 2. Land Degradation in Kalmunai MC, Karativu and Nintavur DSDs 1981-2014 (Source: Computed using GIS, 2015)

The highly degraded land has experienced also a loss of $-5.24 \%$ during the 33 years of observation, which is a sign of deterioration. This class of land has experienced a loss of $-1.49 \%$ (1981 to 1991), $-0.96 \%$ (1991 to 2001), -1.87 (2001 to 2006) and 0.92 (2006-2014) during the various periods in the overall period of analysis. The overall loss of a sizeable proportion of lands in the highly degraded category reveals that measures should be taken on a war footing to preserve the quality of land in the study area (see Figures 3 to 4 ).

It is the evidence from Figure 2 that in the region the non-degraded land has experienced a significant loss of $1.37 \%$ during $1991-2001$ and $2.26 \%$ during $2001-2006$. Further, between 1981 and 2014, the loss in the non-degraded land has accounted for $6.67 \%$ and this indicated that in the study area the extent of non-degraded land has declined so much in a matter of 33 years. The prospect for the future, therefore, looks bleak because there is likely to be greater loss if the present trend continues into the future. 

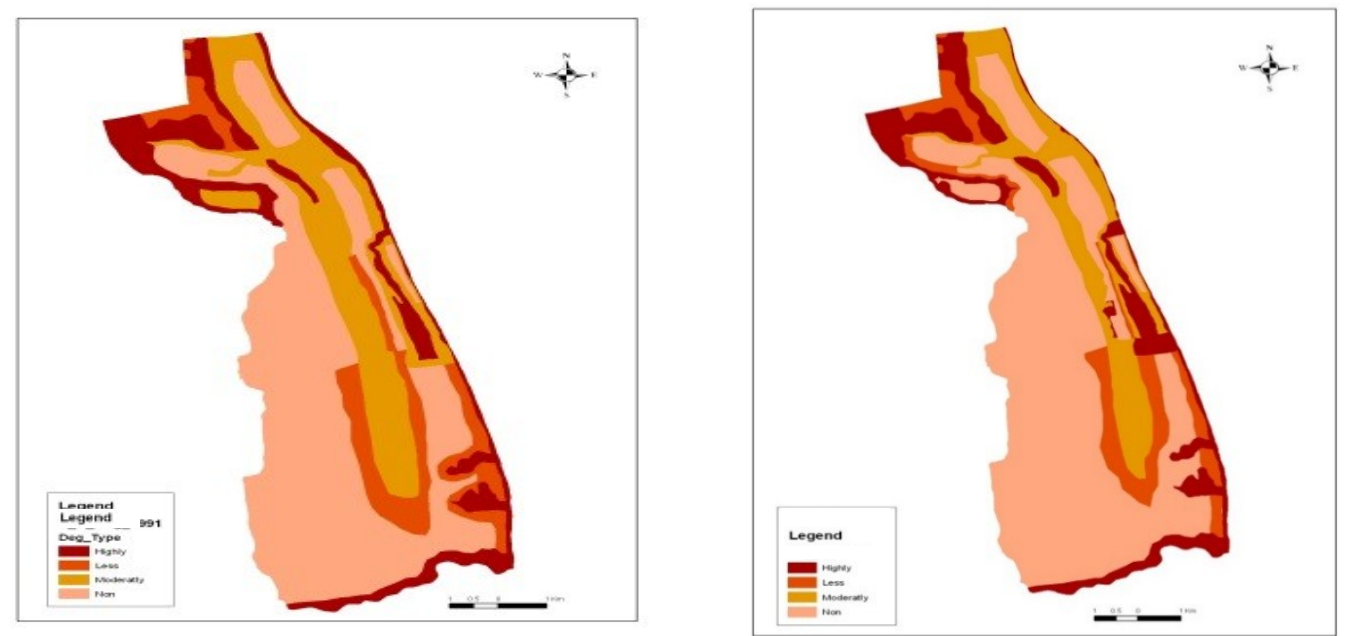

Fig. 3. Land Degradation in Kalmunai MC, Karativu and Nintavur DSDs 1981 and 1991 (Source: Computed using GIS, 2015)

Kalmunai MC has undergone a systematic reduction of highly degraded lands is shown from a steady increase from $26.46 \%$ in 1981 to $31.53 \%$ in 2006 , resulting from the coastal erosion during the years of study. In Karaitivu, there has been a steady decline in the highly degraded lands at $22.40 \%$ and $27.44 \%$ respectively during $1981-1991$ but in $2001-2006$ it registered an increase of about $30.80 \%$. As for Nintavur, the highly degraded land has shown a steady increase from 17.31 $\%$ in 1981 to $24.56 \%$ in 2014 causing coastal and soil erosion.
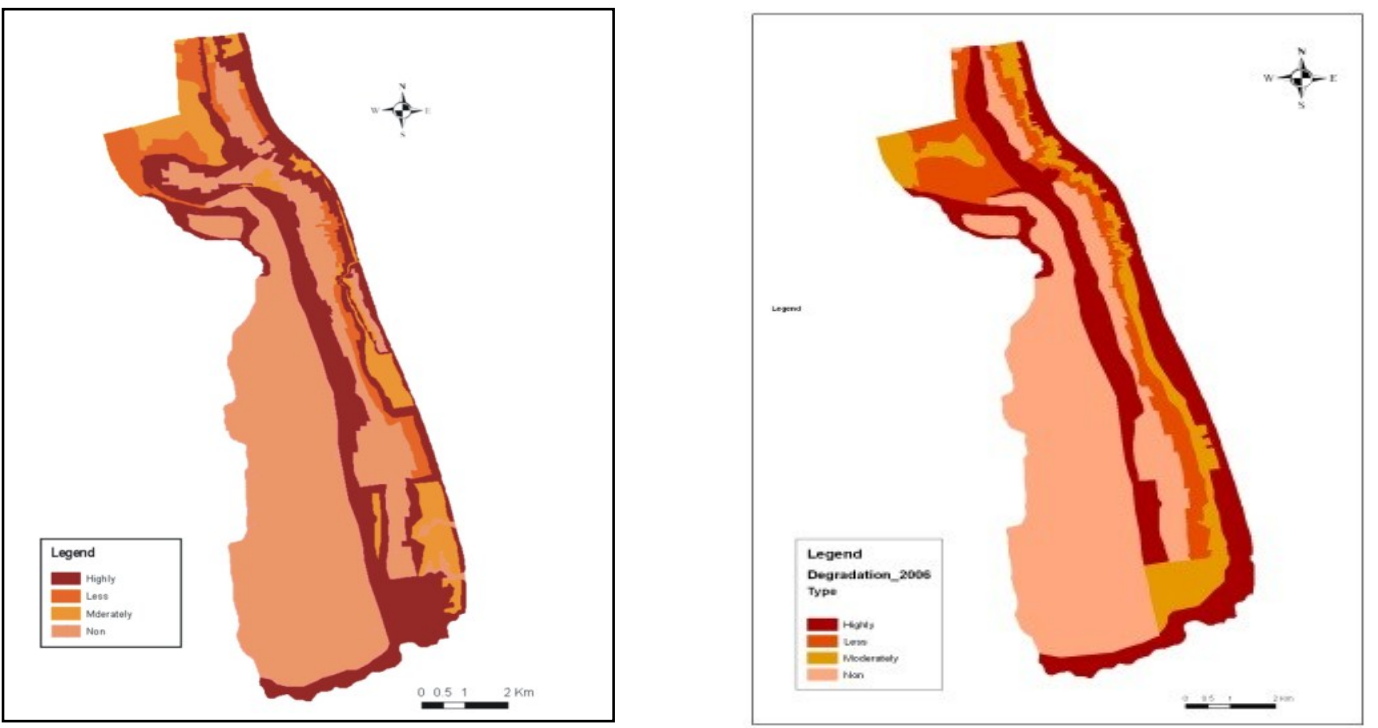

Fig. 4. Land Degradation in Study area 2001 and 2006 (Source: Computed using GIS, 2015) 

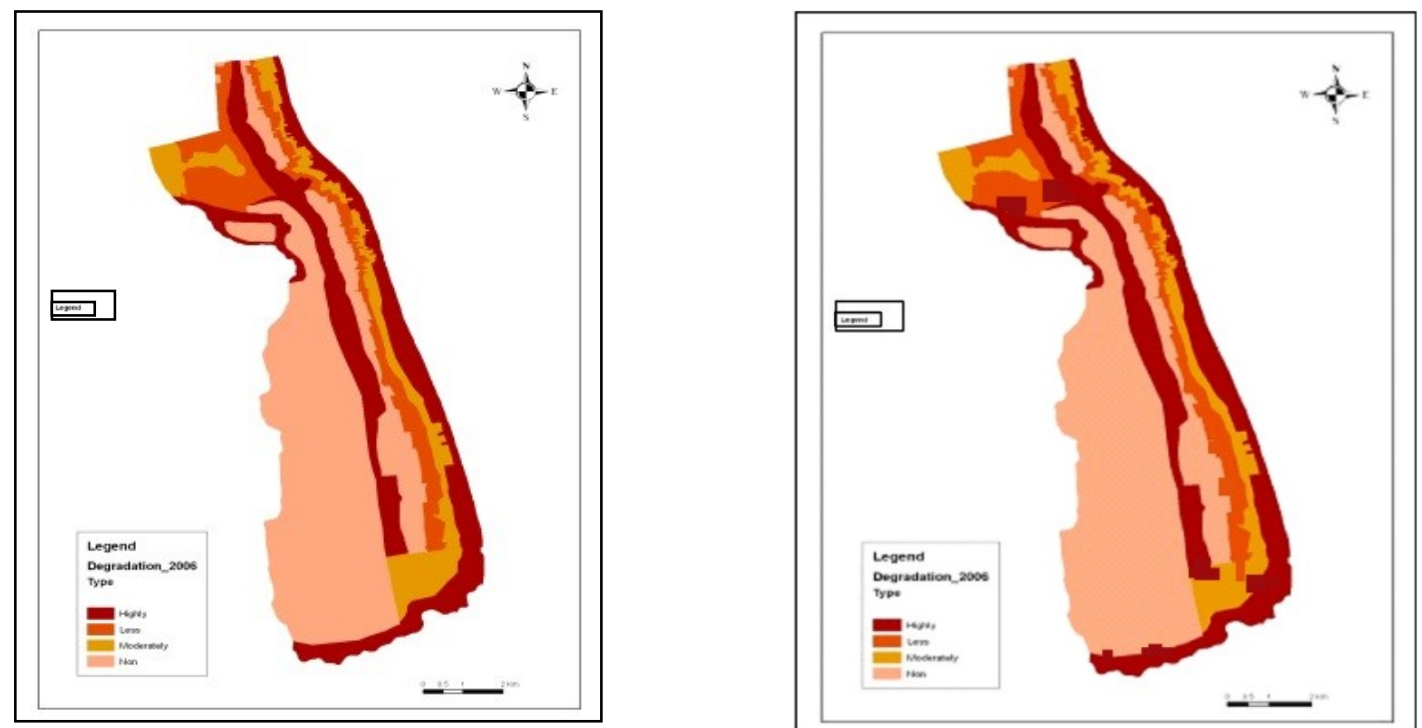

Fig. 5. Land Degradation in Study area 2006 and 2014 (Source: Computed using GIS, 2015)

Kalmunai MC has experienced a systematic reduction of highly degraded lands is shown from a steady increase from $26.46 \%$ in 2006 to $34.25 \%$ in 2014, resulting from the coastal erosion during the years of study. In Karaitivu, there has been a steady decline in the highly degraded lands at $22.40 \%$ and $27.44 \%$ respectively during $1981-1991$ but in $2001-2006$ it registered an increase of about $30.80 \%$. The highly degraded land has shown a steady increase from $17.31 \%$ in 1981 to $24.56 \%$ in 2014 causing coastal and soil erosion.

\section{Causes for the Land degradation}

Coastal Erosion: The coastal erosion has been high for a small proportion of $5.6 \%$ of them, while for nearly $12 \%$ of them, it has been a highly intensive activity along the coast.

Soil Erosion: Very large number of people (32.4\% to be exact) believe it to be low, $26.2 \%$ feel it to be moderate and only $1.3 \%$ of people think it is on the high side.

Flooding: According to their perception, flood is highly hazardous for $14 \%$, moderately affecting for $8.7 \%$ and just about hazardous for $15 \%$ of them.

Tsunami: Nearly $90 \%$ of people have been affected by the tsunami and the third of them have been highly affected, $43.6 \%$ of them have been affected moderately and the level of impact has been rather low for $1.6 \%$ of people.

Decreasing Natural Resource: At $77.8 \%$ of people has felt that there have been very highly decreasing natural resources while a small proposition alone has felt that has been highly decreasing.

Agro-chemicals use: As much as $21.1 \%$ of the people of the people of coastal communities think that there is only moderate use of the chemicals in chemical in the region while nearly $5 \%$ think that there is high use of these that agricultural lands are laid wastes by the excessive chemical uses.

Unclear Roles of Government in Management: For majority of people in the coastal region (45.5 $\%$ ), the role of the provincial government and also the Coastal conservation Department in resources and environmental management are unclear, even as $29.3 \%$ of the people have revealed their roles are normally known.

The following measures are given below to control the land degradation.

1. Control the land fragmentation

2. Population management

3. Control the soil erosion

4. Keep the natural resources

5. Improve the agricultural practices

6. Legislation and policy

7. Awareness programme 


\section{Conclusion}

Based on the analysis of dynamics of land degradation in the study area, the following conclusions have been drawn:

1. The study area has experienced an adverse effect in land degradation throughout the study period 1981-2014.

2. The annual degradation score has shown an increasing trend during 1981 to 1991 and 2001 to 2006, which is an unhealthy development.

3. The negative annual degradation rates indicate a higher level of human interference and disturbance in the normal processes in the study area.

4. Human interference has been the highest and this has been validated by the fact that nearly $70 \%$ of the settlements of the area have shown wider human impacts on the environment.

5. Coastal erosion, Soil erosion, Flooding, Tsunami, and Chemical usages are cause to the land degradation in the study area.

6. There is a strong positive relationship between land degradation and soil erosion as well as land degradation and population density while strong negative relationship can be observed between land degradation and land to man ratio. A sound correlation could not be observed between land degradation and poverty level.

\section{References}

[1] P. A. Burrough, Geographic Information System for Land Resource Assessment. Clarendon Press, Oxford (1986).

[2] S.N. Das, Land Degradation Status in India. BSP.BS Publication, Hyderabad, 4-4- 309:171-177 (2003).

[3] H. Hesadi, K. Jalili and M. Hesadi, Applying RS and GIS for Soil Erosion and Sediment Estimation by MPSIAC Model - A case study of Kenesht watershed in Kermanshah, Iran. (2003).

[4] State of Environment in Sri Lanka, Land Degradation and Natural Hazards in Sri Lanka. Environmental Economics and Global Affairs Division, The Ministry of Environment and Natural Resources, Colombo, Sri Lanka, pp 61-72 (2002).

[5] S. B. St. C. Swan, Coast Erosion Principles and a Classification of South-West Ceylon a beaches on the bias of their Erosional Stability. Bullcey Geogr, Soc. Vol.19 (1965).

[6] L. Venkataratnam and T. Ravisankar, Remote Sensing for Soils and Land Degradation. BSP.BS Publication, Hyderabad, 4-4-309:158-168 (2003).

[7] S. Wijesekera, and L. Samarakoon, Extraction of parameters and modeling soilerosion using GIS in a GRID environment (2001), Retrieved September 27, 2007, from internet: http://www.crisp.nus.edu.sg/ acrs2001/pdf/169wijes. 